\section{University of Edinburgh's woes}

SIR-Your leading article "Academic wall writing" (Nature 326, 114; 1987) rightly points out that universities which regularly receive slightly less than average funding emerge, after a few years, very much worse off than the (itself dismal) average. You conclude that some universities are "on the way down" and may eventually cease to have any role in research, while others may manage to stay afloat.

Your article implies, however, that low funding necessarily means poor research. This is not so. The major factor in determining shifts in the allocation of resources between universities has been what may broadly be termed 'teaching costs'; this has been clearly stated by the University Grants Committee (UGC)'. The adoption of a 'common funding base' by the UGC means that institutions are now allocated a fixed sum for each student in a given subject, with no variation, such as existed previously, between institutions ${ }^{1,2}$. This is expected to account for 61.2 per cent of total resources allocated in 1989-903. Thus, universities that have had aboveaverage costs in the past are penalized while those with lower costs enjoy a relative gain. Many factors contribute to these costs. It is sometimes assumed that high costs betoken idleness, incompetence or other vices, but small classes and old, expensive buildings are more probable interpretations.

The University of Edinburgh is a case in point. You pick it out as having done poorly in the financial distributions. This is true, although several other universities have unfortunately fared still worse, but it is not associated with a low research rating. In the UGC's assessment exercise, some 70 per cent of Edinburgh's departments emerged in cost centres deemed to be above-average for research in the United Kingdom and 10 per cent were rated outstanding. Edinburgh was the fourth largest recipient of external research funds in the United Kingdom in 1984-85, the most recent period for which comparative figures are available ${ }^{4}$, and was in the top 30 per cent even when the figures are corrected to take account of size-differences between the universities. In its letter to the university detailing the basis of the grant for 1986-87, which applies in essence up to $1989-90^{5}$, the UGC stated specifically that research had told in its favour; the main factors that worked against it were the change to a common funding base and some change in the relative numbers of students taking

Letters submitted for Correspondence should be typed, double-spaced, on one side of the paper only. different subjects ${ }^{6}$. In addition, the UGC's planned student numbers for Edinburgh in 1989-90 are (for unknown reasons) nearly 3 per cent below the 1984 85 level, against a 1 per cent overall increase for British universities; this means a further relative reduction in funding. Ironically, the three universities that obtained the lowest external research funding per member of staff in 1984-85 (less than one-third that of Edinburgh) have all been treated more favourably than Edinburgh in the latest UGC distribution.

Similar considerations doubtless apply to some other universities that have fared badly under the UGC's new criteria for resource allocation. Not all have been condemned on their research record. Unfortunately all of them will, as you remark, suffer alike in being unable to recruit young people with new ideas.

H.S MICKLEM

Department of Zoology,

University of Edinburgh,

\section{Edinburgh EH9 3JT, UK}

1. Letter from UGC to universities, 20 May 1986, para 15-16. 2. Review of the University Grants Committee (Report of a committee under the chairmanship of Lord Croham) para 3.42 (HMSO, London, 1987).

3. Review of the University Grants Committee para. 3.43 HMSO, London, 1987).

4. University Statistics Vol. 3 (University Statistical Record, London, 1984/5)

Letter from UGC to universities, 10 February 1987.

6. Letter from UGC to University of Edinburgh, 27 May 1986 Part 2, para. 1

\section{Primitive myth}

SIR-I agree with Bob Johannes ${ }^{1}$ that there is a unique knowledge of marine life among Pacific Islanders and that many traditional maritime activities may have helped to conserve marine resources. We should try to understand these customs better and we should be concerned where they are disappearing.

It is also true, however, that since the 1960 s there has been something of a revival of the Rousseauesque spirit, a guilt about the way 'Western' manners have spread and affected others, and a desire to see something nobler than our own values in non-Western cultures. We should be careful, however, when looking for evidence with which to support such human rights issues that we do not rely solely on speculation.

In his own book on marine lore of the Palau District of Micronesia in the western Pacific, Bob Johannes (ref.2, footnote p.65) concedes that traditional marine tenure may have come into existence in order to reduce conflict, and not overtly to conserve resources. It is evident from other accounts that such tenure was not necessarily based on rational decisions on fisheries management, and may some- times have had nothing to do with such tenure at all ${ }^{3}$.

It is important that we understand the origins of tenure: traditional tenure systems cannot be expected to perform functions in the modern context for which they were not designed. Johannes dismisses evidence for bad resource management ${ }^{4}$, but it is apparent from the response of tenure to new exploitation patterns ${ }^{3}$ that this traditional marine territoriality has limited adaptability to the modern setting. The question still remains as to why, if many Pacific Islanders were purposefully careful of their shallowmarine biological resources, they were not apparently more often mindful of the even more limited and visible terrestrial ones.

N.V.C. Polunin

Department of Zoology,

University of Newcastle upon Tyne, Newcastle upon Tyne NE1 7RU, UK

1. Johannes, R.F. Nature 325, 478 (1987).

. Johannes, R.E. Words of the Lagoon (University of California Press, 1981)

Polunin, N.V.C. Senriethnol. Stud. 17, 267 (1984)

4. Diamond, J.M. Nature 324, 19 (1986).

\section{Problems of Indian science}

SIR-Four decades have passed since India won independence from British rule, which was known for its fair administration. Since then, scientists in medical and non-medical disciplines have suffered frustration, indignation and injustice at the hands of their superiors, so much so that a few have even committed suicide. Paradoxically, no Indian prime minister has been able to curb the activities of those responsible for containing the aspirations of young and promising scientists. If even a few had followed the example of the late Dr Homi J. Bhabha, then head of the Indian Atomic Establishment, their suffering would have been minimal.

In the light of claims and counter-claims made by Indian scientists, both at home and abroad, during the past decade, it is clear that all is not well with the scientific community in the country. The formation of the Society for Scientific Values (see Nature 326, 535; 1987) reveals the truth that it has been infested with several maladies.

The founder of the society is Dr Avtar Singh Paintal, the new director-general of the Indian Council of Medical Research (ICMR). To my knowledge, he is the first director-general to have taken such a lead. One can only hope that the reputation of the present Prime Minister, Mr Rajiv Gandhi who is popularly known as "Mr Clean", will also help scientists to achieve the goal they have set before them.

M.R. DAREKAR

Swiss National Collection

of Type Cultures,

1011 Lausanne, Switzerland 